Document downloaded from:

http://hdl.handle.net/10251/43339

This paper must be cited as:

Rodriguez Martinez, ED.; Bernal, SA.; Provis, JL.; Gehman, JD.; Monzó Balbuena, JM.; Paya Bernabeu, JJ.; Borrachero Rosado, MV. (2013). Geopolymers based on spent catalyst residue from a fluid catalytic cracking (FCC) process. Fuel. 109:493-502. doi:10.1016/j.fuel.2013.02.053.

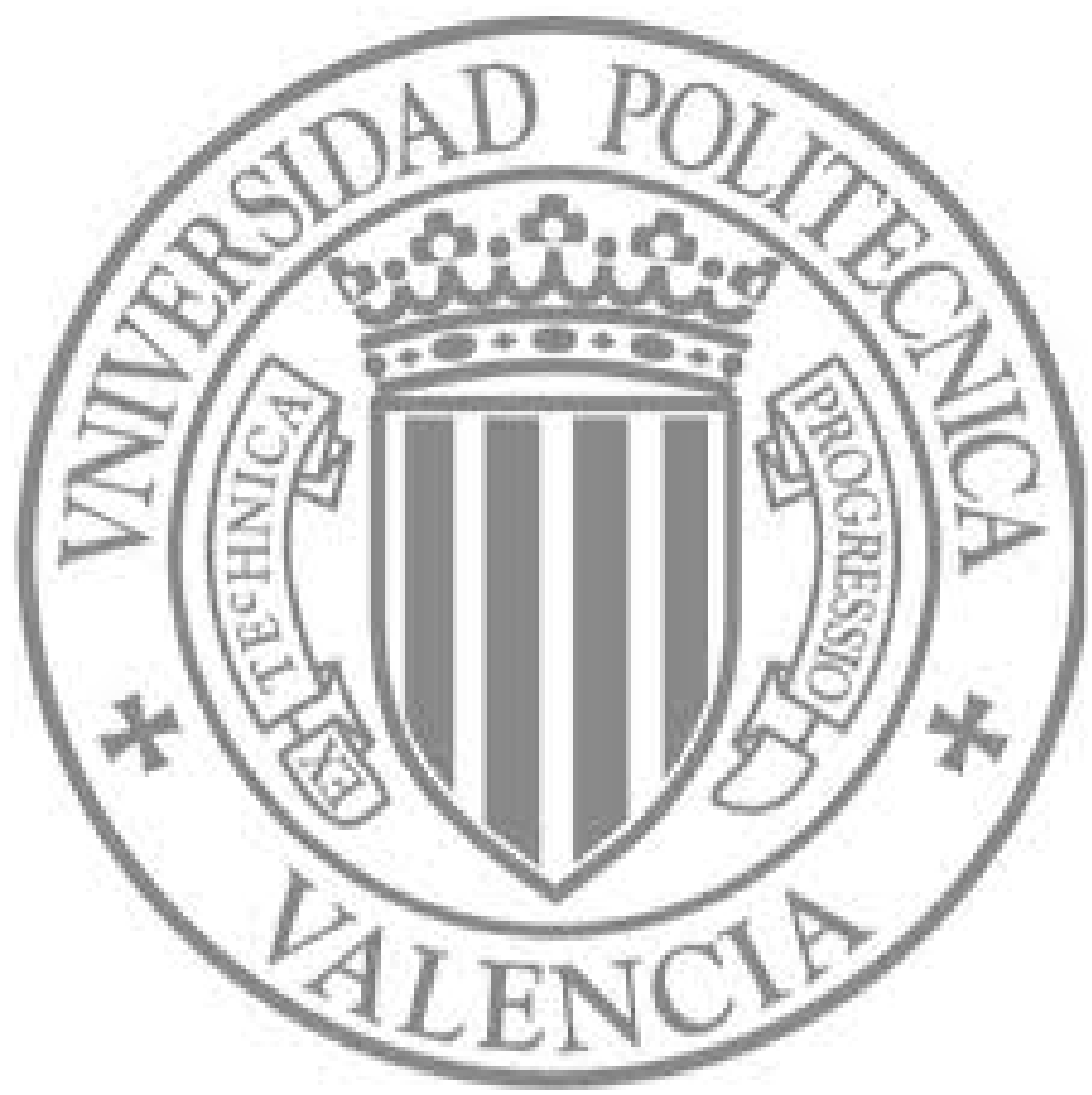

The final publication is available at

http://dx.doi.org/10.1016/j.fuel.2013.02.053

Copyright Elsevier 


\section{Geopolymers based on spent catalyst residue from a fluid catalytic} cracking (FCC) process

\section{Erich D. Rodriguez ${ }^{1,2, t^{*}}$; Susan A. Bernal ${ }^{2,3}$; John L. Provis ${ }^{2,3}$; John D.} Gehman $^{4}$; José M. Monzó ${ }^{1}$; Jordi Payá ${ }^{1}$; M. Victoria Borrachero ${ }^{1}$. *errodnar@disca.upv.es, erichdavidrodriguez@gmail.com

${ }^{1}$ Instituto de Ciencia y Tecnología del Hormigón (ICITECH), Universitat Politècnica de València. Valencia 46022, Spain

2 Department of Chemical and Biomolecular Engineering, University of Melbourne, Victoria 3010. Australia

${ }^{3}$ Department of Materials Science and Engineering, University of Sheffield, Sheffield S1 3JD, United Kingdom

4 School of Chemistry and Bio2 1 Institute, University of Melbourne, Victoria 3010, Australia tCurrent position: Research Fellow. Grupo de Materiales Compuestos. Universidad del Valle. Cali, Colombia

\section{Abstract}

This paper assesses the use of alkali activation technology in the valorization of a spent Fluid Catalytic Cracking (FCC) catalyst, which is a residue derived from the oil-cracking process, to produce 'geopolymer' binders. In particular, the effects of activation conditions on the structural characteristics of the spent catalyst-based geopolymers are determined. The zeolitic phases present in the spent catalyst are the main phases participating in the geopolymerization reaction, which is driven by the conversion of the zeolitic material to a highly Al-substituted aluminosilicate binder gel. Higher alkali content and $\mathrm{SiO}_{2} / \mathrm{Na}_{2} \mathrm{O}$ ratio lead to a denser structure with a higher degree of geopolymer gel formation and increased degree of crosslinking, as identified through ${ }^{29} \mathrm{Si}$ MAS NMR. These results highlight the feasibility of using spent FCC catalyst as a precursor for geopolymer production.

\begin{tabular}{|l|}
\hline Con formato: Español (Colombia) \\
\hline $\begin{array}{l}\text { Con formato: Fuente: Sin Negrita, Sin } \\
\text { Cursiva, Español (Colombia) }\end{array}$ \\
\hline Con formato: Español (Colombia) \\
\hline $\begin{array}{l}\text { Comentario [ER1]: Should I put my } \\
\text { current position..?? }\end{array}$ \\
\hline
\end{tabular}


36 Keywords Geopolymer; Fluid catalytic cracking; catalyst residue, zeolites 


\section{Introduction}

Catalysis is a widely used process in the petrochemical industry for the transformation of crude oil to gasoline and other fuel products, with an economic impact estimated at more than 6.3 million barrels per day in 2012 in the U.S. alone [1]. A wide range of zeolites and molecular sieves are commonly used in the fluid catalytic cracking $(\mathrm{FCC})$ process, but the catalysts are degraded when in use. Partial or complete regeneration of spent FCC catalyst can be carried out in some cases, although in the longer term its continual reuse is not possible due to irreversible deactivation and structural damage to the zeolitic material. More than 400 petroleum refineries worldwide refine crude oil via fluid cracking catalytic units [2], and $\sim 160,000$ tons of spent catalyst residue are produced every year by the petrochemical industry. However, with an anticipated 5\% annual increase in catalyst consumption, the spent catalyst residue may exceed 200,000 tons annually within a few years [3]. This residue mainly consists of $\mathrm{SiO}_{2}$ and $\mathrm{Al}_{2} \mathrm{O}_{3}$, and can be considered as an agglomeration of zeolite crystals (mainly zeolite $\mathrm{Y}$ in the case of the material studied here) held together by an aluminosilicate matrix.

During the cracking reactions, the surface of FCC catalyst particles can be contaminated with different cations (including $\mathrm{Ni}, \mathrm{V}, \mathrm{Fe}, \mathrm{Cu}$ and/or $\mathrm{Na}$ ), and coke (carbon) is deposited in ppm levels or more. According to the European waste catalogue (commission 94/3EEC), spent FCC catalyst (code 160804) is classified as a non-hazardous material and has been used in landfill, as a source of $\mathrm{SiO}_{2}$ and $\mathrm{Al}_{2} \mathrm{O}_{3}$ in the Portland cement clinkerization process [4], as a filler in asphaltic concretes [5], as a substitute for kaolin in the ceramic industry [6], as a raw material in the synthesis of some zeolites or for extraction of active $\mathrm{Al}_{2} \mathrm{O}_{3}[7,8]$, in the production of bricks through sintering processes [9], in the refractory industry [10] and as a supplementary cementitious material (SCM) in blended cement production [11-15].

The inclusion of spent FCC catalyst as an SCM in Portland cement blends can lead to an increase in the mechanical strength and the improvement of some durability properties as a consequence of its high reactivity with $\mathrm{Ca}(\mathrm{OH})_{2}$ $[12,13]$. The zeolitic structures in spent FCC catalyst have the ability to 
promote the formation of an Al-substituted C-S-H type gel (via the pozzolanic reaction) and/or hydrated aluminate phases [16]. The presence of some contaminants, such as $\mathrm{Ni}$, can reduce the pozzolanic reactivity of the spent catalyst, and so the potential use of spent FCC catalysts in the production of Portland cement-based building materials must be very carefully assessed $[14,17]$. It has been reported that mechanical [18], thermal [19], and chemical treatments [20] can enhance the effectiveness of spent FCC catalyst as an SCM in ordinary Portland cement systems.

Geopolymers are materials with properties similar to those of hardened Portland cement, produced through the alkali activation of an aluminosilicate precursor [21,22]. The geopolymer structure is dominated by an aluminosilicate type gel, comparable with an amorphous zeolite structure [23]. The interest in geopolymers as a potential alternative to Portland cement has increased considerably during the last two decades, as these materials can present technical, environmental and economic advantages when compared with conventional cements. Geopolymer production is associated with lower energy consumption and lower $\mathrm{CO}_{2}$ emissions compared with the Portland cement industry, as well as the benefit of providing a pathway to the valorization of high-volume reactive aluminosilicate industrial wastes or byproducts [22].

Depending on the raw materials selected and their processing conditions, geopolymers can exhibit high compressive strengths, moderate shrinkage, and good performance when exposed to aggressive environments such as strong acids and high temperatures [23]. Industrial by-products such as fly ash from coal combustion, metallurgical slags, natural minerals including calcined clays, and volcanic ashes, have been successfully used as aluminosilicate precursors in the production of geopolymer systems [24]. However, the availability of those precursors in some parts of the world is limited, and therefore, there is an increasing need to identify different precursors with similar chemical and structural properties that can be widely available. Considering that spent FCC catalyst is a reactive aluminosilicate material which is produced in relatively high volumes and which does not currently have a direct pathway to valorization, it is likely that this material is a feasible precursor for the larger- 
scale synthesis of geopolymers; it has recently been demonstrated [25] that alkali-activation might be a desirable alternative for the valorization of this byproduct.

The aim of the present study is to analyze in more detail the potential application of alkali-activation of spent FCC catalyst waste to produce alternative binders, through the development of a better understanding of the structural features of a new spent FCC catalyst-based geopolymer. The effect of the alkali and silicate content in the structure of spent FCC catalyst-based geopolymers is determined using X-ray diffraction (XRD), Fourier transmission transform infrared spectroscopy (FTIR), solid state nuclear magnetic resonance spectroscopy (NMR), and scanning electron microscopy (SEM).

\section{Experimental Program}

\subsection{Materials}

Spent fluid catalytic cracking catalyst was supplied by BP Oil España (Castellon, Spain), and prior to activation was subjected to a mechanical treatment using a ball mill (Mill-2 Gabrielli) for 20 minutes to increase its reactivity $[12,26]$. Figure 1 shows the destruction of the spent fluid catalytic cracking catalyst particles as a consequence of the mechanical treatment applied. The particle size range determined by laser granulometry was $0.8-100$ $\mu \mathrm{m}$ with a mean particle diameter of $17.1 \mu \mathrm{m}$. According to the chemical composition (table 1), the spent $\mathrm{FCC}$ catalyst has a $\mathrm{SiO}_{2} / \mathrm{Al}_{2} \mathrm{O}_{3}$ ratio close to unity. The total silica content determined in previous studies following the procedure suggested by Payá et al [27] was $48.3 \%$, while the reactive silica content determined by a $\mathrm{KOH}(4 \mathrm{M})$ attack was $41.3 \%$.

Figure 1. Scanning electron micrographs of A. untreated spent FCC catalyst and B. ball-milled FCC catalyst. 
Table 1. Chemical composition of the spent fluid catalytic cracking catalyst used, on an oxide basis, from X-ray fluorescence analysis. LOI is loss on ignition.

The catalyst residue contains different crystalline zeolite phases, which are identifiable through XRD (Figure 2), with the use of the Powder Diffraction File (PDF) and American Mineralogist Crystal Structure Database (AMCSD) reference resources. The faujasite type-structure of dehydrated dealuminated US-Y zeolite $\left(\left|\mathrm{Al}_{5.6} \mathrm{O}_{22.4}\right| \cdot\left[\mathrm{Si}_{175.7} \mathrm{Al}_{16.3} \mathrm{O}_{384}\right]\right.$, PDF \# 00-045-0112), ZSM-5 zeolite $\left(\mathrm{M}_{\mathrm{n}} \mathrm{Al}_{\mathrm{n}} \mathrm{Si}_{(96-\mathrm{n})} \mathrm{O}_{192} \cdot 16 \mathrm{H}_{2} \mathrm{O} ; \mathrm{n}<27 ; \quad \mathrm{PDF} \#\right.$ 00-044-0002) and mordenite $\left(\left(\mathrm{Ca}, \mathrm{Na}_{2}, \mathrm{~K}_{2}\right) \mathrm{Al}_{2} \mathrm{Si}_{10} \mathrm{O}_{24} \cdot 7 \mathrm{H}_{2} \mathrm{O} ; \mathrm{AMCSD} \#\right.$ 0003444) were observed. Different hightemperature aluminosilicate polymorphs such as sillimanite $\left(\mathrm{Al}_{2} \mathrm{SiO}_{5} ; \mathrm{PDF}\right.$ \# 00-038-0471), kyanite ( $\mathrm{Al}_{2} \mathrm{SiO}_{5} ; \mathrm{PDF} \#$ 00-011-0046), and mullite $\left(3 \mathrm{Al}_{2} \mathrm{O}_{3} \cdot 2 \mathrm{SiO}_{2}\right.$; PDF \# 00-015-0776), as well as quartz $\left(\mathrm{SiO}_{2}, \mathrm{PDF} \#\right.$ 00-0461045), were also identified. Sillimanite and kyanite are used as active fillers in catalysts in the petroleum industry [28]; non-catalytic or non-reactive aluminasilica compounds are used in the catalyst to remove carbonaceous and metallic contaminants ( $\mathrm{Ni}$ or V) [29]. The spent FCC catalyst also has a high content of amorphous (glassy) aluminosilicate phases as a consequence of the partial destruction of the zeolite structures by the inclusion of lanthanum and titanium during catalyst synthesis [30], and also in service. Lanthanum oxide $\left(\mathrm{La}_{2} \mathrm{O}_{3}, \mathrm{PDF} \# 00-022-0641\right)$ and some traces of aluminum titanium silicate ( $\mathrm{Al}_{4} \mathrm{Ti}_{2} \mathrm{SiO}_{12}$; PDF \# 00-022-0502) and anatase ( $\mathrm{TiO}_{2}, \mathrm{PDF} \#$ 00-021-1272) were also identified.

As alkali activators, sodium silicate solutions were used, synthesized by blending distilled water, analytical grade sodium hydroxide pellets $(\mathrm{NaOH}$; Sigma-Aldrich, Australia) and a commercial sodium silicate solution (PQ Silicates, Australia) with 28.7 wt.\% $\mathrm{SiO}_{2}, 8.9$ wt.\% $\mathrm{Na}_{2} \mathrm{O}$ and 62.4 wt.\% $\mathrm{H}_{2} \mathrm{O}$. The proportions of water, $\mathrm{NaOH}$ and sodium silicate were adjusted to produce alkali activators with compositions $\mathrm{Na}_{2} \mathrm{O} \cdot r \mathrm{SiO}_{2} \cdot 11 \mathrm{H}_{2} \mathrm{O}$, where $r=0,1.0$, and 2.0 . 2.0 


\subsection{Sample preparation}

The spent FCC catalyst was activated with activator doses of 7 wt.\%, 10 wt.\% and 15 wt.\% of $\mathrm{Na}_{2} \mathrm{O}$, relative to the mass of spent catalyst residue, and a water/catalyst residue ratio of 0.50 . The mix designs are given in Table 2 .

Table 2. Mix designs of geopolymer samples

The pastes were mixed for three minutes and then poured into a plastic container and sealed for curing at $40^{\circ} \mathrm{C}$ for 28 days. Samples were milled, washed with acetone to halt the reaction process, and stored sealed until characterization.

\subsection{Tests conducted}

The reaction products, and structures of the geopolymers produced, were assessed through:

- X-ray diffraction (XRD) using a Bruker D8 Advance instrument with Nifiltered $\mathrm{Cu} \mathrm{K}_{\alpha}$ radiation, with a step size of $0.020^{\circ}$ and $4 \mathrm{~s} /$ step.

- Fourier transform infrared (FTIR) spectroscopy via the $\mathrm{KBr}$ pellet technique, using a Bruker Tensor 27 spectrometer and 32 scans per spectrum. Spectra were collected in transmittance mode from 4000 to $400 \mathrm{~cm}^{-1}$ at a resolution of $4 \mathrm{~cm}^{-1}$.

- Solid-state ${ }^{29} \mathrm{Si}$ and ${ }^{27} \mathrm{Al}$ magic angle spinning nuclear magnetic resonance (MAS NMR) spectra were obtained on a Varian Direct Drive VNMRS-600 spectrometer (14.1 T) using a MAS NMR probe for $4 \mathrm{~mm}$ o.d. zirconia rotors and a spinning speed of $v_{R}=10.0 \mathrm{kHz}$. ${ }^{29} \mathrm{Si}$ MAS NMR experiments were acquired using a pulse width of $4 \mu \mathrm{s}$ and a relaxation delay of $20 \mathrm{~s}$, and 3664-4096 scans. ${ }^{27} \mathrm{Al}$ MAS NMR experiments were conducted at $156.3 \mathrm{MHz}$ on the same instrument, with a pulse width of $0.5 \mu \mathrm{s}$, a relaxation delay of $2 \mathrm{~s}$, and 1024 scans. ${ }^{29} \mathrm{Si}$ and ${ }^{27} \mathrm{Al}$ chemical shifts are referenced to external samples of tetramethylsilane (TMS) and a $1.0 \mathrm{M}$ aqueous solution of $\mathrm{Al}\left(\mathrm{NO}_{3}\right)_{3} \cdot 9 \mathrm{H}_{2} \mathrm{O}$, respectively.

- Scanning electron microscopy (SEM) was conducted using a FEI Quanta microscope (ESEM) with $15 \mathrm{kV}$ accelerating voltage. The samples were 
evaluated in low vacuum mode to enable the analysis of uncoated fracture surfaces.

\section{Results and Discussion}

\subsection{X-ray diffraction (XRD)}

The alkali-activation of the catalyst residue leads to the dissolution of the faujasite type zeolite (identified by XRD, as dehydrated, dealuminated zeolite Y), as shown in Figure 2 by the disappearance of the peaks assigned to this phase in the geopolymer samples. A higher alkalinity (lower $\mathrm{SiO}_{2} / \mathrm{Na}_{2} \mathrm{O}$ ratios) leads also to the dissolution of mordenite, whose peaks decrease with increasing alkali content. This behavior is also observed with higher $\mathrm{SiO}_{2} / \mathrm{Na}_{2} \mathrm{O}$ ratios in the silicate-activated systems.

Figure 2. X-ray diffractograms of the spent FCC catalyst based geopolymers after 28 days of curing

Some of the crystalline aluminosilicate phases identified in the unreacted spent FCC catalyst (Figure 2), such as mullite, kyanite and sillimanite, along with quartz, are observed in the geopolymer samples regardless of the activation conditions used. This is consistent with the known behavior of mullite and quartz in fly ash-based geopolymers, where these crystalline phases are seen to be unreactive [31]. However, the intensities of the peaks assigned to kyanite do decrease when the catalyst residue is activated with $15 \% \mathrm{Na}_{2} \mathrm{O}$, especially when the $\mathrm{SiO}_{2} / \mathrm{Na}_{2} \mathrm{O}$ ratio is also high (sample 15N2). 
The higher deviation of the XRD data from the baseline at increased alkali content is attributed to the formation of a highly amorphous new gel, consistent with the well-known geopolymer gel [32]. The degree of amorphicity of this gel is controlled by the degree of polycondensation and/or the $\mathrm{SiO}_{2} / \mathrm{Na}_{2} \mathrm{O}$ ratio [33]. The higher amorphicity identified in the silicate-activated systems with high alkalinity (such as $15 \mathrm{~N} 1$ and 15N2) can contribute to enhancement of the mechanical performance according to the results previously obtained by Tashima et al [25]. In that study, it was identified when producing FCC catalyst-based geopolymers that increasing the hydroxide concentration and the inclusion of soluble silica in the alkali activator promotes increased compressive strength, reaching values of up to $68 \mathrm{MPa}$ after 3 days of curing at $65^{\circ} \mathrm{C}$.

The absence of the diffraction peaks corresponding to the US-Y zeolite and the reduction of the mordenite peaks in the geopolymer samples, when compared with the unreacted catalyst residue (Figure 2), indicate that these phases are participating in the geopolymerization reactions. There was no new crystalline phase identified as a reaction product in the geopolymer samples. Albite, which was identified as a main crystalline phase in alkali-activated spent FCC catalyst geopolymers [25], was not identified in this study. Other products such as hydrosodalite that have been widely observed in metakaolin-based and fly ash-based geopolymers [34-36] were also not identified in these samples.

\subsection{Fourier transform infrared (FTIR) spectroscopy}

Infrared spectra of the unreacted spent FCC catalyst, and the alkali-activated pastes with different alkali concentrations and different $\mathrm{SiO}_{2} / \mathrm{Na}_{2} \mathrm{O}$ ratios, are shown in Figure 3. The spectra obtained were normalized in order to enable a direct comparison between the different geopolymers produced. 
Figure 1․ Fourier transform infrared spectra of alkali-activated spent FCC catalys geopolymers after 28 days of curing

The band between 1200-950 $\mathrm{cm}^{-1}$ in the spectrum of the spent FCC catalyst residue is associated with the asymmetric stretching vibration mode of Si-O-T bonds ( $\mathrm{T}$ : tetrahedral $\mathrm{Si}$ or $\mathrm{Al}$ ), which is often called the "main band" in geopolymer spectra $[37,38]$. This band is centered at $1090 \mathrm{~cm}^{-1}$, corresponding to the asymmetric stretching of $\mathrm{Si}-\mathrm{O}-\mathrm{Si}$ bonds, which also show resonances due to symmetric stretching and bending modes at $\sim 800 \mathrm{~cm}^{-1}$ and $459 \mathrm{~cm}^{-1}$, respectively [37,38]. The shoulder observed at $1185 \mathrm{~cm}^{-1}$ and the signal between 560-550 $\mathrm{cm}^{-1}$ are associated with the octahedrally coordinated aluminum present in the kyanite, mullite and sillimanite previously identified by XRD (Figure 2), and also potentially the mordenite in the spent residue, which might also contain some octahedral Al in extra-framework sites as consequence of the high temperatures to which the material is exposed during its use as a catalyst [39]. Tetrahedrally coordinated aluminum in the aluminosilicate phases is identified by the asymmetric stretch vibration of the $\mathrm{AlO}_{4}^{-}$groups at $833 \mathrm{~cm}^{-1}$.

The peaks located at $833,789,611$, and $528 \mathrm{~cm}^{-1}$ correspond to the asymmetric, symmetric, double 6-ring and bending vibration modes of the aluminosilicate framework in dealuminated Y zeolites [40]. Additional peaks at 1078, 1176 and $1206 \mathrm{~cm}^{-1}$ are also observed in dealuminated Y zeolites [39], but the signals of other Si-rich phases overlap these bands in the samples studied here. Zeolites have two types of acidity: Brønsted acid sites involving hydroxyl groups, and Lewis acid sites associated with three-coordinated framework aluminum or with extra-framework Al containing species, which can be identified at $\sim 1400-1450 \mathrm{~cm}^{-1}$ in the spectra in Figure 3 [41]. Brønsted sites are observed via a band at $3000-3500 \mathrm{~cm}^{-1}$ (not shown in Figure 3) and an additional band at $1632 \mathrm{~cm}^{-1}$, associated with the bending vibration mode of $-\mathrm{OH}$ bonds in the mordenite structure [37,42]. The presence of the bands centered at $\sim 1425$ and $2360 \mathrm{~cm}^{-1}$ is likely to indicate the presence of some traces of ammonium cations and/or nitrile species which remain adsorbed on zeolites after its use as a catalyst [43]. 


\subsubsection{Effect of alkali content.}

The alkali activation of spent FCC catalyst leads to the destruction of the zeolitic structures according to the XRD results (Figure 2), and the development of new amorphous phases with different structural and bonding features. The main band in the spectra of the unreacted spent FCC catalyst is reduced in intensity and broadened after alkali activation at 7 wt. $\% \mathrm{Na}_{2} \mathrm{O}$. This broad band identified in the geopolymers activated at 7 wt.\% $\mathrm{Na}_{2} \mathrm{O}$ indicates structural disorder in the silicate-aluminate network, and potentially an incomplete degree of polymerization in the geopolymer product.

However, at higher alkali concentrations $\left(15 \mathrm{wt} . \% \mathrm{Na}_{2} \mathrm{O}\right)$, this peak is narrowed and significantly more intense as a consequence of the higher extent of dissolution of the aluminosilicate precursor, contributing more silicate and aluminate species for geopolymer gel formation. Increased alkali content leads to a shift of the main (asymmetric stretch) band in spent FCC catalyst-based geopolymers towards lower wavenumbers, as a consequence of a higher content of Al incorporation into the geopolymer gel [44]. The intensity of this main band, and the extent of the shift to lower wavenumbers, depend on the degree of crosslinking and the chemical nature of the gel framework formed during the geopolymerization [45,46]. Activation with a higher alkali concentration accelerates the dissolution of the aluminosilicate species in the precursor, which can lead to an enhanced rate of geopolymer network formation [46]. However, excess alkalinity can also lead to a reduced extent of gel deposition and/or re-dissolution of the gel, because the concentration required to achieve supersaturation in the solution phase is higher, affecting the properties of the final binder product obtained [23].

The activation process leads to a reduction in the intensities of the bands observed in the unreacted spent FCC catalyst at $460 \mathrm{~cm}^{-1}, 528 \mathrm{~cm}^{-1}$ and 609 $\mathrm{cm}^{-1}$, which is associated with the dissolution of the zeolite phases. The geopolymer product shows new bands at $\sim 725 \mathrm{~cm}^{-1}$ and $\sim 850 \mathrm{~cm}^{-1}$ attributed to the stretching vibration of $\mathrm{Si}-\mathrm{O}-\mathrm{Si}(\mathrm{Al})$ bridges, and stretching vibration modes of $\mathrm{AlO}_{4}$ sites, respectively [47]. The band at $725 \mathrm{~cm}^{-1}$ becomes stronger 
and sharper at increased alkali contents (10 wt.\% to 15 wt.\% $\mathrm{Na}_{2} \mathrm{O}$ ), which is attributed to a higher degree of Al substitution in the Si-rich gel.

In silicate-activated systems with high alkalinity $(10 \mathrm{~N} 1,10 \mathrm{~N} 2,15 \mathrm{~N} 1$ and 15N2), the new band between $880-900 \mathrm{~cm}^{-1}$, observed as a small shoulder on the main Si-O-T band, is assigned to the stretching vibration mode of Al-O bonds in condensed $\mathrm{AlO}_{4}^{-}$groups. The band at $\sim 584-590 \mathrm{~cm}^{-1}$ can be assigned to cyclosilicate vibrations whose intensity and width is associated with the Al and $\mathrm{Si}$ content in the geopolymer gel, along with the degree of structural disorder and/or deformation of the six-membered rings in the geopolymer gel structure. The fact that this band is observable and distinct indicates that the gel is relatively ordered.

The band at $1632 \mathrm{~cm}^{-1}$ in the spectrum of the unreacted spent FCC catalyst becomes more intense, and shifts slightly towards higher wavenumber $(\sim 1650$ $\mathrm{cm}^{-1}$ ) in the geopolymer pastes, as a consequence of the presence of more adsorbed hydroxyl groups ( $\left(\mathrm{Si}-\mathrm{OH} \cdots \mathrm{H}_{2} \mathrm{O}\right.$ and $\left.\equiv \mathrm{Al}-\mathrm{OH} \cdots \mathrm{H}_{2} \mathrm{O}\right)$ in the geopolymer gel [48]. This band does not change significantly with alkali content.

\subsubsection{Effect of silica content}

The "main band" in the geopolymer spectra in Figure 3 shifts toward slightly higher wavenumber with increasing $\mathrm{SiO}_{2} / \mathrm{Na}_{2} \mathrm{O}$ ratio, regardless of the alkali content of the system. The main band for the geopolymer $15 \mathrm{NO}\left(\mathrm{SiO}_{2} / \mathrm{Na}_{2} \mathrm{O}\right.$ ratio of 0 ) is centered at $1001 \mathrm{~cm}^{-1}$, and shifts to $1024 \mathrm{~cm}^{-1}$ when an alkali activator with a $\mathrm{SiO}_{2} / \mathrm{Na}_{2} \mathrm{O}$ ratio of 2.0 is used. Similar behavior is also observed at lower alkali contents, where the main band of $10 \mathrm{~N} 1$ at $1016 \mathrm{~cm}^{-1}$ shifts to $1032 \mathrm{~cm}^{-1}$ when the activator $\mathrm{SiO}_{2} / \mathrm{Na}_{2} \mathrm{O}$ ratio is increased from 1.0 to 2.0 (10N2). This shift in the main band is attributed to the reduced bond length and/or increasing bond angle in the Si-O-T bonds as a consequence of a higher content of $\mathrm{SiO}_{2}$ and higher extent of crosslinking, consistent with the formation of a Si-rich gel with a reduced $\mathrm{Al}$ content, along with a reduction in the fraction of silicon sites with non-bridging oxygens $\left(\mathrm{Q}^{3}\right.$ sites) [45,49-51]. Additionally, the 
bands at 584 and $725 \mathrm{~cm}^{-1}$ shift towards higher wavenumbers, which is also a consequence of the more Si-rich environment in the gel.

The band corresponding to the bending vibration mode of $-\mathrm{OH}\left(\sim 1650 \mathrm{~cm}^{-1}\right)$ is shifted slightly towards lower wavenumber with an increased $\mathrm{SiO}_{2} / \mathrm{Na}_{2} \mathrm{O}$ ratio, which is attributed to a potential increase in the prevalence of the $\mathrm{O}-\mathrm{H} \cdots \mathrm{O}$ bond interaction in the gel [52]. This could take place as the gel densifies and becomes more compact, as the $\mathrm{O}-\mathrm{H}$ bonds of water molecules in the pores are forced to interact more closely with the bridging oxygen atoms of the framework.

\subsection{Nuclear magnetic resonance spectroscopy (MAS NMR)}

\subsection{1. ${ }^{27}$ Al MAS NMR}

The ${ }^{27} \mathrm{Al}$ MAS NMR spectrum of the unreacted spent FCC catalyst (Figure 4) shows broad bands in the regions assigned to octahedrally (-10 to $30 \mathrm{ppm})$, pentahedrally (30 to $50 \mathrm{ppm}$ ) and tetrahedrally (50 to $80 \mathrm{ppm}$ ) coordinated $\mathrm{Al}$ sites. Considering that this precursor is composed of a variety of zeolite phases, along with other Al-containing minerals, as has previously been identified by XRD (Figure 2), none of these peaks can unambiguously be assigned to the contribution of a single phase.

Figure 3ㅁ. Solid state ${ }^{27} \mathrm{Al}$ MAS NMR spectra $\left(14.1 \mathrm{~T}, v_{\mathrm{R}}=10 \mathrm{kHz}\right)$ of geopolymers, recorded after 28 days of curing.

The breadth of the ${ }^{27} \mathrm{Al}$ resonances in these high-resolution, high-field spectra suggests the presence of substantial amounts of disordered Al-containing phases. The spectrum of the spent FCC catalyst (Figure 4) shows somewhat 
sharp, high intensity peaks at $10 \mathrm{ppm}$ and $58 \mathrm{ppm}$, which are assigned respectively to the resonances of 6 - and 4-coordinated aluminum species in ordered environments. These are consistent with the sillimanite [53], kyanite [54] and zeolite [55] structures identified by XRD in section 3.1. A low intensity signal at $28 \mathrm{ppm}$ is also identified, which could be attributed to surface defect sites in the dehydrated dealuminated US-Y zeolite [56]. The broad signals observed between 30-50 ppm may be indicating the presence of aluminum species in a disturbed tetrahedral coordination (AlV) or penta-coordinated species (Alv) [57-59].

In service in the catalytic cracking process, the FCC catalyst undergoes further hydrothermal dealumination, leading to removal of up to $90 \mathrm{wt} \%$ of the tetrahedrally-coordinated aluminum from the zeolite framework, and consequently, hydroxyl groups associated with silicon replace aluminumcontaining bonds [60]. These silanol groups are associated with the formation of a secondary mesopore surface and other structural defects induced by the loss of aluminum, resulting in a more potentially reactive material. The presence of distorted species containing tetrahedrally coordinated $\mathrm{Al}$, as a result of the partial destruction of the framework while the material is in service as a catalyst, is consistent with the amorphous hump observed in the $\mathrm{X}$-ray diffractogram of the unreacted spent catalyst (Figure 2).

Changes in the line shape of the ${ }^{27} \mathrm{Al}$ NMR spectrum after activation, compared to the unreacted spent catalyst, are a strong indication of which phases are participating in the geopolymerization reaction, and also provide a measure of the structural characteristics of the newly-formed gel. After the activation of the spent catalyst, the band at $28 \mathrm{ppm}$ has almost completely disappeared as a consequence of the dissolution of the US-Y zeolite phase, independent of the alkali concentration used during the activation process, which is consistent with the results obtained by XRD (Figure 2). The spectrum also shows a decrease in the intensity of the resonance at $10 \mathrm{ppm}$, more pronounced at higher alkali contents. The dissolution of the dealuminated Y zeolite is also identified through the disappearance of the resonance attributed to octahedral Al. The low intensity remnant 6-coordinated Al band observed after alkaliactivation is attributed to the residual mullite phase [61], which remains 
invariant in the XRD, and therefore seems not to participate in the geopolymerization reaction process.

The narrow resonance of $\mathrm{AlO}_{4}$ groups $(58 \mathrm{ppm})$ in the spent $\mathrm{FCC}$ catalyst becomes broader with the alkali activation, which is associated with the formation of a highly crosslinked disordered aluminosilicate gel type, being the main reaction product in alkali-activated aluminosilicate binders [62], and consistent with the aluminosilicate (geopolymer) gel identified by FTIR and XRD above. Geopolymers with low alkali content (such as the $7 \mathrm{~N}$ systems, regardless of $\mathrm{SiO}_{2} / \mathrm{Na}_{2} \mathrm{O}$ ratio) show only a slight shift in the AlVI resonance compared with the unreacted FCC catalyst. On the other hand, at higher alkali content (especially for geopolymers $15 \mathrm{~N}$ ), the spectra exhibit a very notable decrease in the intensity of AlVI sites, and a corresponding increase in Alv. This effect is identified at all $\mathrm{SiO}_{2} / \mathrm{Na}_{2} \mathrm{O}$ ratios in the $15 \mathrm{~N}$ systems. The strong signal of this tetrahedral $\mathrm{Al}$ species $(\sim 58 \mathrm{ppm})$ for the $15 \mathrm{~N} 1$ and $15 \mathrm{~N} 2$ geopolymers indicates a very highly polymerized structure among the $\mathrm{Q}^{4}(n \mathrm{Al})$ silicate species.

\subsection{1. ${ }^{29}$ Si MAS NMR}

${ }^{29}$ Si MAS NMR spectroscopy was carried out for two selected silicate-activated systems, and the unreacted FCC residue (Figure 5). The spent catalyst contains silica and alumina present within various phases, such as zeolites and other aluminosilicate minerals, and thus a wide range of silicon environments can be identified as discussed throughout this study. The spectrum of the unreacted spent FCC catalyst is consistent with the presence of highly dealuminated zeolites (peak at $-107 \mathrm{ppm}$ ), and also contains a distribution of $\mathrm{Q}^{3}(n \mathrm{Al})$ and $\mathrm{Q}^{4}(n \mathrm{Al})$ sites, with $n$ between 0 and 4 [63], as well as sites where the $\mathrm{Si}$ is associated with octahedral as well as tetrahedral sites, as in the mullite, kyanite and sillimanite structures. The narrow resonance at $-107 \mathrm{ppm}$ is mainly attributed to the $\mathrm{Q}^{4}(\mathrm{OAl})$ sites of the US-Y zeolite [64]. Although a resonance in this position can also be attributed to quartz, the absence of this peak in the spent catalyst-based geopolymers, and the XRD results (Figure 2) where the US-Y zeolite is not observed and the small amount of quartz present 
is still identified in activated pastes, it is likely that the intensity of these peaks is mainly contributed by the remnant US-Y zeolite. Given the extremely slow relaxation times of ${ }^{29} \mathrm{Si}$ in quartz ( $\mathrm{T}_{1}$ values on the order of an hour have been measured for quartz in the instrument used here, compared to the recycle delay of $20 \mathrm{~s}$ used here), it is likely that any quartz sites remained close to saturated throughout the experiment, and thus contributed very little to the measured spectra.

Figure 4ㅁ. Solid state ${ }^{29} \mathrm{Si}$ MAS NMR spectra $\left(14.1 \mathrm{~T}, v_{\mathrm{R}}=10 \mathrm{kHz}\right)$ of geopolymers recorded after 28 days of curing

The broad resonance centered at around $-113 \mathrm{ppm}$ is in agreement with the resonances typically identified in mordenite [65], ZSM-5 zeolite [66], as well as highly dealuminated US-Y zeolite (steamed at high temperature) [64]. According to Klinowski et al. [65], the $\mathrm{Q}^{4}(3 \mathrm{Al}), \mathrm{Q}^{4}(2 \mathrm{Al})$ and $\mathrm{Q}^{4}(1 \mathrm{Al})$ sites from the amorphous component of deactivated zeolite phases composing the spent FCC catalyst should be located at $-94.5,-101.5$ and $-103 \mathrm{ppm}$, respectively. The high concentration of $\mathrm{Q}^{4}$ species is coherent with the high intensity of the bands identified in the FTIR spectra (Figure 3) at $1090 \mathrm{~cm}^{-1}$ and $459 \mathrm{~cm}^{-1}$. A site at around $-87 \mathrm{ppm}$ is able to be assigned to several of the different aluminosilicate polymorphs identified by XRD: mullite, sillimanite and kyanite. While this site cannot be assigned to an individual silicon environment in these materials, it best is described as an sillimanite-type site, where the $\mathrm{SiO}_{4}$ tetrahedron is surrounded by three $\mathrm{AlO}_{4}$ and one $\mathrm{AlO}_{6}$ polyhedra [54,67]. This is consistent with the mullite, sillimanite and kyanite structures as identified by XRD (Figure 2), and the presence of the 4-coordinated and 6-coordinated Al sites identified in the ${ }^{27} \mathrm{Al}$ MAS NMR of the alkali-activated catalyst residue (Figure 4).

As a function of the degree of dealumination of the zeolites, the formation of terminal hydroxyl groups in environments such as $\mathrm{Si}(\mathrm{OSi})_{3} \mathrm{OH}$ and $\mathrm{Si}(\mathrm{OSi})_{2}(\mathrm{OH})_{2}$ species $\left(\mathrm{Q}^{3}\right.$ and $\mathrm{Q}^{2}$ sites respectively) can be promoted at the outer surface or internal defect sites [55]. While it is difficult to clearly 
distinguish these sites in the spectrum of the unreacted spent catalyst, it is likely that these sites make a small contribution to the broad resonance identified in the spectra in Figure 5 between -90 and -100 ppm.

The alkali-activation of the spent catalyst promotes the formation of an intense, asymmetric broad band centered at $-92 \mathrm{ppm}$, associated with the formation of an aluminosilicate type gel. In the $7 \mathrm{~N} 2$ geopolymers, a shoulder is observed in the region between $-100 \mathrm{ppm}$ and $-120 \mathrm{ppm}$, attributed to the $\mathrm{Q}^{4}$ sites of the remnant dealuminated zeolites from the spent catalyst that have not been completely consumed during the geopolymerization reaction. Taking into account the XRD results (Figure 2), it is likely that US-Y zeolite contributions are not observed in this region, as it seems that this phase is consumed during the geopolymerization reaction even at low alkalinity conditions. The resonances in the region between $-80 \mathrm{ppm}$ and $-100 \mathrm{ppm}$ are assigned to the $\mathrm{Q}^{4}(n \mathrm{Al})$ sites of the newly formed geopolymer gel, consistent with the formation of a three dimensional highly crosslinked type gel, as previously observed by ${ }^{29} \mathrm{Si}$ MAS NMR in other low-calcium geopolymers [68] These results are consistent with the trends observed by FTIR in these samples, as higher wavenumbers of the FTIR bands attributed to the T-O-T bonds are identified at higher alkali content (Figure 3).

The spectrum of the geopolymer sample formed at higher alkali content (15N2) shows a reduction in the intensity of the shoulder between $-100 \mathrm{ppm}$ and -120 ppm, as observed in the $7 \mathrm{~N} 2$ geopolymers. This suggests a higher extent of dissolution of the dealuminated zeolite phases of the spent catalyst at higheralkalinity activation conditions, as was suggested from the FTIR results in Figure 3. Additionally, the spectrum of $15 \mathrm{~N} 2$ is slightly narrowed compared to that of the $7 \mathrm{~N} 2$ geopolymer, indicating a higher degree of ordering of the aluminosilicate type gel formed at higher alkalinity conditions, which has also been identified in the ${ }^{27} \mathrm{Al}$ MAS NMR results (Figure 4) via the sharpening of the 4-coordinated Al band at increased alkalinity. There is a slight increment in the intensity in the region between $-80 \mathrm{ppm}$ and $-100 \mathrm{ppm}$ in the $15 \mathrm{~N} 2$ spectrum compared to the $7 \mathrm{~N} 2$ binders, as a consequence of the higher degree of $\mathrm{Al}$ incorporation in the aluminosilicate gel. This is consistent with the 
increased intensity of the AlV region in the $15 \mathrm{~N} 2$ geopolymers in Figure 4, and the increased intensity of the FTIR band at $725 \mathrm{~cm}^{-1}$ in Figure 3, at higher alkaline contents.

The spectra of reacted and unreacted spent FCC catalyst materials could not be deconvoluted into component Gaussian peaks for quantification of the component peaks, as the remnant spent FCC catalyst in the geopolymer samples contributes to the spectrum in the region consistent with $\mathrm{Q}^{4}(3 \mathrm{Al})$, $\mathrm{Q}^{4}(2 \mathrm{Al})$ and $\mathrm{Q}^{4}(1 \mathrm{Al})$ sites. This region thus overlaps with the highly crosslinked sites in the geopolymer gel formed, making it impossible to predict which particular sites within the unreacted spent catalyst dissolve faster than others, as it is unknown whether the amorphous component of the remnant precursor embedded in the geopolymer binders is in a gel type structure or in a glass type structure, and also whether there is any $\mathrm{Al}^{\mathrm{VI}}$ present within this amorphous component. Further research therefore needs to be conducted in this area before spectral deconvolution could be reliably conducted.

\subsection{Scanning electron microscopy (SEM)}

Figure 6 shows SEM images of spent catalyst based geopolymers formulated with different alkali concentrations and an $\mathrm{SiO}_{2} / \mathrm{Na}_{2} \mathrm{O}$ molar ratio of 1.0. The images show morphological differences in the gels formed, as a function of alkalinity. The geopolymers show a rough, heterogeneous structure, and the presence of partially reacted FCC catalyst particles (compare to unreacted particles in Figure 1), which leads to the formation of a spongy structure at low alkali content $(7 \mathrm{~N} 1)$. This is probably less desirable in terms of binder performance and permeability than the denser and more homogeneous structure of the $15 \mathrm{~N} 1$ binder. The more homogeneous structure for $15 \mathrm{~N} 1$ is consistent with the higher dissolution and polymerization degree identified above, which leads to the formation of an aluminosilicate gel product with a higher cross-linking degree [69]. 
Figure $5 \underline{6}$. Scanning electron micrographs of pastes with different alkali content (A. $7 \mathrm{~N} 1$, B. $10 \mathrm{~N} 1$, and C. $15 \mathrm{~N} 1$ ) after 28 days of curing.

Figure 7 shows micrographs of the fracture surfaces of spent FCC catalystbased geopolymers activated with 15 wt.\% $\mathrm{Na}_{2} \mathrm{O}$, with different $\mathrm{SiO}_{2} / \mathrm{Na}_{2} \mathrm{O}$ ratios. The silicate-activated systems (Figure 7B,C) exhibit a denser gel structure with fewer large interconnected pores, as well as fewer unreacted particles from the aluminosilicate precursor. It is expected that the improvement in structural homogeneity of the geopolymers promotes the development of improved performance and enhanced durability as observed in [25], and consistent with results obtained in other geopolymer systems based on different aluminosilicate precursors, such as metakaolin [68] and fly ashes [35]. The increase in the silica content from system $15 \mathrm{~N} 1$ to $15 \mathrm{~N} 2$ does not show to promote significant differences in the gel structure, but the less favorable rheology of the highest-silica system seems to have led to the inclusion of a greater number of relatively large air bubbles in this specimen.

Figure 6- 7 Scanning electron micrographs of pastes with different $\mathrm{SiO}_{2} / \mathrm{Na}_{2} \mathrm{O}$ ratio (A. $15 \mathrm{~N}$, B. $15 \mathrm{~N} 1$, and C. $15 \mathrm{~N} 2$ ) after 28 days of curing.

\section{Conclusions}

This study has demonstrated the potential of a zeolite-based spent fluid catalytic cracking catalyst as an effective precursor for the production of geopolymer binders. In these systems, the remnant dealuminated zeolites in the unreacted spent residue are readily dissolved, even when activation is carried out under relatively low alkalinity conditions, indicating the high reactivity of this precursor during the alkali-activation reaction. Increased alkali contents lead to the formation of a highly dense and crosslinked aluminosilicate type gel, when compared with the gels formed at lower alkali content, which were enriched in $\mathrm{Si}$ and present a rather heterogeneous structure with interconnected pores. This is related to the high alkalinity 
required to promote the dissolution of the $\mathrm{AlO}_{4}^{-}$species from the distorted zeolite structures and other phases present in the spent catalyst. This is consistent with the fact that independent of the alkali content, an increased reactive $\mathrm{SiO}_{2} / \mathrm{Al}_{2} \mathrm{O}_{3}$ ratio promotes the formation of highly crosslinked Sienriched type gels with low Al content. This work then provides the basis for further developments in this area, as a means of valorizing spent fluid catalytic cracking catalyst residues into useful geopolymer materials.

\section{Acknowledgments}

This study was sponsored by research scholarship BES-2008-002440 and EEBB-2011-43847 from the Ministerio de Ciencia y Tecnología of Spain, the European regional development fund (FEDER), and the Universitat Politècnica de València (Spain). The participation of SAB and JLP was funded by the Australian Research Council through the Discovery Projects program, and also including partial funding through the Particulate Fluids Processing Centre, a Special Research Centre of the ARC. The authors wish to acknowledge the Advanced Microscopy Facility at The University of Melbourne for assistance with the electron microscopy experiments conducted in this study.

\section{References}

[1] EIA Independent Statistics \& Analysis, U.S. Energy Information Administration. Shortterm energy outlook. September 2012.

[2] Speight J G. The chemistry and technology of petroleum ( $4^{\text {th }}$ edition). CRC Press. Taylor \& Francis Group, LLC. New York. 2006.

[3] Marafi M, Stanislaus A, Furimsky E. Handbook of spent hydroprocessing catalysts: Regeneration, rejuvenation, reclamation, environment and safety. 1st edition. ISBN: 9780-444-53556-6. Elsevier. Amsterdam, The Netherlands 2010. 
[4] Schreiber R, Yonley G. The use of spent catalyst as a raw material substitute in cement manufacturing, ACS Petrol Chem Div Preprints 1993;38:97-9.

[5] Lin J, Tarn J, Yu D, Hsiao L. Utilization of ROC spent catalyst on asphalt concrete. In: International Conference on Industrial Waste Minimization, Taiwan; 1995, p. 667-74.

[6] Escardino A, Amoros J, Moreno A, Sanchez E. Utilizing the used catalyst from refinery FCC units as a substitute for kaolin in formulating ceramic frits. Waste Manag Res 1995;13:569-78.

[7] Basaldellaa EI, Torres RM, Conconi MS. Conversion of exhausted fluid cracking catalysts into zeolites by alkaline fusion. Appl Clay Sci 2009;42:611-4.

[8] Al-Sheeha H, Marafi M, Stanislaus A. Reclamation of alumina as boehmite from an alumina-supported spent catalyst. Int J Miner Process 2008;88:59-64.

[9] Sun DD. Stabilization treatment for reutilization of spent refinery catalyst into valueadded product. Energ Source 2003;25:607-15.

[10] Stonys R, Pundiene I, Antonovic V, Goberis S, Aleknevicius M. The effect of waste oilcracking catalyst on the properties of MCC-type castable. Mater Sci-Medzg 2008;14:5962.

[11] Pacewska B, Wilińska I, Kubissa J. Use of spent catalyst from catalytic cracking in fluidized bed as a new concrete additive, Thermochim Acta 1998;322:175-81.

[12] Payá J, Monzó J, Borrachero MV. Fluid catalytic cracking catalyst residue ( FC3R ): An excellent mineral by-product for improving early-strength development of cement mixtures. Cement Concrete Res 1999;29:1773-9.

[13] Chen H-L, Tseng Y-S, Hsu K-C. Spent FCC catalyst as a pozzolanic material for highperformance mortars. Cement Concrete Compos 2004;26:657-64.

[14] Dweck J, Pinto CA, Buchler P. Study of a Brasilian spent catalyst as cement aggregate by thermal and mechanical analysis. J Therm Anal Calorim 2008;92:121-7.

[15] García de Lomas M, Sánchez de Rojas M, Frías M. Pozzolanic reaction of a spent fluid catalytic cracking catalyst in FCC-cement mortars. J Therm Anal Calorim 2007;90:443-7.

[16] Glasser FP, Zornoza E, Garcés P, Payá J, Brew DRM. Pozzolanic activity of a spent fluid catalytic cracking catalyst residue. Adv Cem Res 2011; 23:105-11.

[17] Bayraktar O. Bioleaching of nickel from equilibrium fluid catalytic cracking catalysts. World J Microb Biot 2005;21:661-5. 
[18] Pacewska B, Wilinska I, Bukowska M, Blonkowski G, Nocun-Wczelik W. An attempt to improve the pozzolanic activity of waste aluminosilicate catalyst. J Therm Anal Calorim 2004;77:133-42.

[19] Hsu K-C, Tseng J-S., Ku F-F, Su N. Oil cracking waste catalyst as an active pozzolanic material for superplasticized mortars. Cement Concrete Res 2001;31:1815-20.

[20] Payá J, Monzó J, Borrachero MV, Velázques S. Chemical activation of pozzolanic reaction of fluid catalytic cracking catalyst residue in lime pastes. Adv Cem Res 2004;16:123-30.

[21] Roy DM. Alkali-activated cements Opportunities and challenges. Cement Concrete Res 1999;29:249-54.

[22] van Deventer JSJ, Provis JL, Duxson P. Technical and commercial progress in the adoption of geopolymer cement. Miner Eng 2012;29:89-104.

[23] Provis JL, van Deventer JSJ. Geopolymers. Structure, processing, properties and industrial applications. Woodhead Publishing, Cambridge; 2009.

[24] Duxson P, Provis JL. Designing precursors for geopolymer cements. J Am Ceram Soc 2008;91:3864-9.

[25] Tashima MM, Akasaki JL, Castaldelli VN, Soriano L, Monzó J, Payá J, et al. New geopolymeric binder based on fluid catalytic cracking catalyst residue (FCC). Mater Lett 2012;80:50-52.

[26] Payá J, Monzó J, Borrachero MV, Velázquez S, Bonilla M. Determination of the pozzolanic activity of fluid catalytic cracking residue. Thermogravimetric analysis studies on FC3R-lime pastes. Cement Concrete Res 2003;33:1085-91.

[27] Payá J, Monzó J, Borrachero MV, Mellado A, Ordoñez LM. Determination of amorphous silica in rice husk ash by a rapid analytical method, Cement Concrete Res 2001;31(2):227-31.

[28] Kolesnikov IM, Frolova IN. Production and activity of sillimanite and sillimanite-zeolite aluminosilicate catalyst. J Appl Chem USSR 1982;55:561-71.

[29] Reagan WJ, White DW, Schultz WR, Jarnagin LA, Pitts F. Mullite/silica contact material, its production, and its use in selective vaporization of petroleum feedstock, European Patent EP 0185551; 1986.

[30] Liu C, Deng Y, Pan Y, Zheng S, Gao X. Interactions between heavy metals and clay matrix in fluid catalytic cracking catalysts. Appl Catal A-General 2004; 257:145-50. 
[31] Fernández-Jiménez A, Delatorre A, Palomo A, Lopezolmo G, Alonso M, Aranda M. Quantitative determination of phases in the alkali activation of fly ash. Part I. Potential ash reactivity. Fuel 2006;85:625-34.

[32] Rahier H, Mele B, Biesemans M, Wastiels J, Wu X. Low-temperature synthesized aluminosilicate glasses. J Mater Sci 1996;31:71-79.

[33] Rahier H, Simons W, Van Mele B, Biesemans M. Low-temperature synthesized aluminosilicate glasses: Part III Influence of the composition of the silicate solution on production, structure and properties. J Mater Sci 1997;32:2237-47.

[34] De Silva P, Sagoe-Crenstil K. Medium-term phase stability of $\mathrm{Na}_{2} \mathrm{O}-\mathrm{Al}_{2} \mathrm{O}_{3}-\mathrm{SiO}_{2}-\mathrm{H}_{2} \mathrm{O}$ geopolymer systems. Cement Concrete Res 2008;38:870-6.

[35] Criado M., Fernández-Jiménez A, de la Torre A, Aranda M, Palomo A. An XRD study of the effect of the $\mathrm{SiO}_{2} / \mathrm{Na}_{2} \mathrm{O}$ ratio on the alkali activation of fly ash. Cement Concrete Res 2007;37:671-9.

[36] van Deventer JSJ, Provis JL, Duxson P, Lukey GC. Reaction mechanisms in the geopolymeric conversion of inorganic waste to useful products. J Hazard Mater 2007;139:506-13.

[37] Farmer VC. The infrared spectra of minerals, Royal Society, London; 1974.

[38] Gadsden JA. Infrared spectra of minerals and related inorganic compounds, Butterworth, London, U.K.; 1975.

[39] Bugaev LA, van Bokhoven JA, Sokolenko AP, Latokha YV, Avakyan LA. Local structure of aluminum in zeolite mordenite as affected by temperature. J Phys Chem B 2005;109:10771-10778.

[40] Miessner H, Kosslick H, Lohse U, Parlitz B, Tuan VA. Characterization of highly dealuminated faujasite-type zeolites: ultrastable zeolite Y and ZSM-20. J Phys Chem 1993;97:9741-8.

[41] Masukawa T, Komatsu T, Yashima T. Alkylation of toluene on HSAPO-5 with various Si concentrations. Zeolites 1997;19:429-33.

[42] Li B, González RD. An in situ DRIFTS study of the deactivation and regeneration of sulfated zirconia. Catal Today 1998;46:55-67.

[43] Damjanović L, Auroux A. Determination of acid/base properties by temperature programmed desorption (TPD) and adsorption calorimetry, in: A.W. Chester, E.G. Derouane (Eds.), Zeolite Characterization and Catalysis, Springer Netherlands; 2010: p. $107-67$. 
[44] Flanigen EM. Structural analysis by infrared spectroscopy. In: Zeolite Chemistry and Catalysis. American Chemical Society, 1976; ACS Monograph Series, Washington, D.C.

[45] Rees CA, Provis JL, Lukey GC, van. Deventer JSJ. Attenuated total reflectance Fourier transform infrared analysis of fly ash geopolymer gel aging. Langmuir 2007;23:8170-9.

[46] Rees CA, Provis JL, Lukey GC, van Deventer JSJ. In Situ ATR-FTIR study of the early stages of fly ash geopolymer gel Formation. Langmuir 2007;23:9076-82.

[47] Lecomte I, Henrist C, Liégeois M, Maseri F, Rulmont A, Cloots R. (Micro)-structural comparison between geopolymers, alkali-activated slag cement and Portland cement. J Eur Ceram Soc 2006;26:3789-97.

[48] Zhang Z, Wang H, Provis JL, Bullen F, Reid A, Zhu Y. Quantitative kinetic and structural analysis of geopolymers. Part 1 . The activation of metakaolin with sodium hydroxide, Thermochim Acta 2012;539:23-33.

[49] Fernández-Jiménez A, Palomo A. Mid-infrared spectroscopic studies of alkali-activated fly ash structure. Micropor Mesopor Mater 2005;86:207-14.

[50] Fernández-Jiménez A, Palomo A, Sobrados I, Sanz J. The role played by the reactive alumina content in the alkaline activation of fly ashes. Micropor Mesopor Mater 2006;91:111-9.

[51] Devine RAB. Ion implantation- and radiation-induced structural modifications in amorphous $\mathrm{SiO}_{2}$. J Non-Cryst Solids 1993;152:50-58.

[52] Liu X. Infrared and Raman spectroscopy, in: A.W. Chester, E.G. Derouane (Eds.), Zeolite Characterization and Catalysis, Springer Netherlands, 2010: p. 197-222.

[53] He H, Guo J, Zhu J, Yuan P, Hu C. ${ }^{29} \mathrm{Si}$ and ${ }^{27} \mathrm{Al}$ MAS NMR spectra of mullites from different kaolinites. Spectrochim Acta A 2004;60:1061-4.

[54] Hartman JS, Sherriff BL. Silicon-29 MAS NMR of the aluminosilicate mineral kyanite: residual dipolar coupling to aluminum-27 and nonexponential spin-lattice relaxation. J Phys Chem 1991;95:7575-9.

[55] Engelhardt G, Lohse U, Samoson A, Mägi M, Tarmak M, Lippmaa E, High resolution ${ }^{29} \mathrm{Si}$ NMR of dealuminated and ultrastable Y-zeolites. Zeolites 1982;2:59-62.

[56] Behera B, Ray SS. Structural changes of FCC catalyst from fresh to regeneration stages and associated coke in a FCC refining unit: A multinuclear solid state NMR approach. Catal Today 2009;141:195-204.

[57] Engelhardt G, Michel D. High-resolution solid-state NMR of silicates and zeolites, John Wiley and Sons, New York; 1987. 
[58] Chen T-H, Houthoofd K, Grobet PJ, Toward the aluminum coordination in dealuminated mordenite and amorphous silica-alumina: A high resolution ${ }^{27} \mathrm{Al}$ MAS and MQ MAS NMR study. Micropor Mesopor Mater 2005;86:31-7.

[59] Rocha J, Carr SW, Klinowski J. ${ }^{27} \mathrm{Al}$ quadrupole nutation and ${ }^{1} \mathrm{H}^{-27} \mathrm{Al}$ cross-polarization solid-state NMR studies of ultrastable zeolite $\mathrm{Y}$ with fast magic-angle spinning. Chem Phys Lett 1991;187:401-8.

[60] Rakiewicz EF, Mueller KT, Jarvie TP, Sutovich KJ, Roberie TG, Peters AW. Solid-state NMR studies of silanol groups in mildly and highly dealuminated faujasites. Micropor Mater 1996;7:81-8.

[61] Merwin LH, Sebald A, Rager H, Schneider H. ${ }^{29} \mathrm{Si}$ and ${ }^{27} \mathrm{Al}$ MAS NMR spectroscopy of mullite. Phys Chem Miner 1991;18:47-52.

[62] Duxson P, Lukey GC, Separovic F, van Deventer JSJ. Effect of alkali cations on aluminum incorporation in geopolymeric gels. Ind Eng Chem Res 2005;44:832-9.

[63] Fyfe BCA, Thomas JM, Klinowski J, Gobbi GC. Magic-angle-spinning NMR (MASNMR) spectroscopy and the structure zeolites. Angew Chem Int Ed 1983;22:259-75.

[64] Gore KU, Abraham A, Hegde SG, Kumar R, Amoureux J-P, Ganapathy S. MAS / 3QMAS NMR Studies of High Silica USY Zeolites. J Phys Chem B 2002;106:6115-20.

[65] Barras J, Klinowski J, Mccomb DW. ${ }^{27}$ AI and ${ }^{29}$ Si Solid-state NMR Studies of dealuminated mordenite. J Chem Soc Faraday Trans 1994:90:3719-23.

[66] Klinowski J. Recent Advances in Solid-State NMR of Zeolites. Annu Rev Mater Sci 1988;18:189-218.

[67] Jaymes I, Massiot D, Coutures J-P. Evolution of the Si environment in mullite solid solution by ${ }^{29}$ Si MAS-NMR spectroscopy. J Non-Cryst Solids 1996;204:125-34.

[68] Duxson P, Provis JL, Lukey GC, Separovic F, van Deventer JSJ. ${ }^{29}$ Si NMR study of structural ordering in aluminosilicate geopolymer gels. Langmuir 2005;21:3028-36.

[69] Duxson P, Provis JL, Lukey GC, Mallicoat SW, Kriven WM, van Deventer JSJ. Understanding the relationship between geopolymer composition, microstructure and mechanical properties. Colloids Surfaces A 2005;269:47-58.
Con formato: Normal (Web), Sangría: Izquierda: $0 \mathrm{~cm}$, Sangría francesa: 1,13 cm, Interlineado: Múltiple 1,3 lín. 
818 Table 1. Chemical composition of the spent fluid catalytic cracking catalyst 819 used, on an oxide basis, from X-ray fluorescence analysis. LOI is loss on 820 ignition.

\begin{tabular}{cc}
\hline Compound & Wt.\% \\
\hline $\mathrm{SiO}_{2}$ & 46.94 \\
$\mathrm{Al}_{2} \mathrm{O}_{3}$ & 48.40 \\
$\mathrm{Fe}_{2} \mathrm{O}_{3}$ & 0.59 \\
$\mathrm{CaO}$ & 0.11 \\
$\mathrm{MgO}$ & 0.17 \\
$\mathrm{SO}$ & 0.02 \\
$\mathrm{~K}_{2} \mathrm{O}$ & 0.02 \\
$\mathrm{Na}_{2} \mathrm{O}$ & 0.31 \\
$\mathrm{TiO}_{2}$ & 1.20 \\
$\mathrm{P}_{2} \mathrm{O}_{5}$ & 0.01 \\
$\mathrm{Nd}_{2} \mathrm{O}_{3}$ & 0.04 \\
$\mathrm{~V}_{2} \mathrm{O}_{5}$ & 0.01 \\
$\mathrm{La}_{2} \mathrm{O}_{3}$ & 1.36 \\
$\mathrm{CeO}_{2}$ & 0.12 \\
$\mathrm{Pr}_{2} \mathrm{O}_{3}$ & 0.19 \\
$\mathrm{LOI}_{\left(950^{\circ} \mathrm{C}\right)}$ & 0.50 \\
\hline
\end{tabular}

821

822 
824 Table 2. Mix designs of geopolymer samples

\begin{tabular}{ccc}
\hline Geopolymer & $\begin{array}{c}\text { Alkali content } \\
\left(\text { wt. } \% \mathrm{Na}_{2} \mathrm{O}\right)\end{array}$ & $\begin{array}{c}\mathrm{SiO}_{2} / \mathrm{Na}_{2} \mathrm{O} \text { molar } \\
\text { ratio in alkali } \\
\text { activator }\end{array}$ \\
\hline $7 \mathrm{NO}$ & 7 & 0 \\
$7 \mathrm{~N} 1$ & 7 & 1.0 \\
$7 \mathrm{~N} 2$ & 7 & 2.0 \\
$10 \mathrm{NO}$ & 10 & 0 \\
$10 \mathrm{~N} 1$ & 10 & 1.0 \\
$10 \mathrm{~N} 2$ & 10 & 2.0 \\
$15 \mathrm{NO}$ & 15 & 0 \\
$15 \mathrm{~N} 1$ & 15 & 1.0 \\
$15 \mathrm{~N} 2$ & 15 & 2.0 \\
\hline
\end{tabular}

825

826 

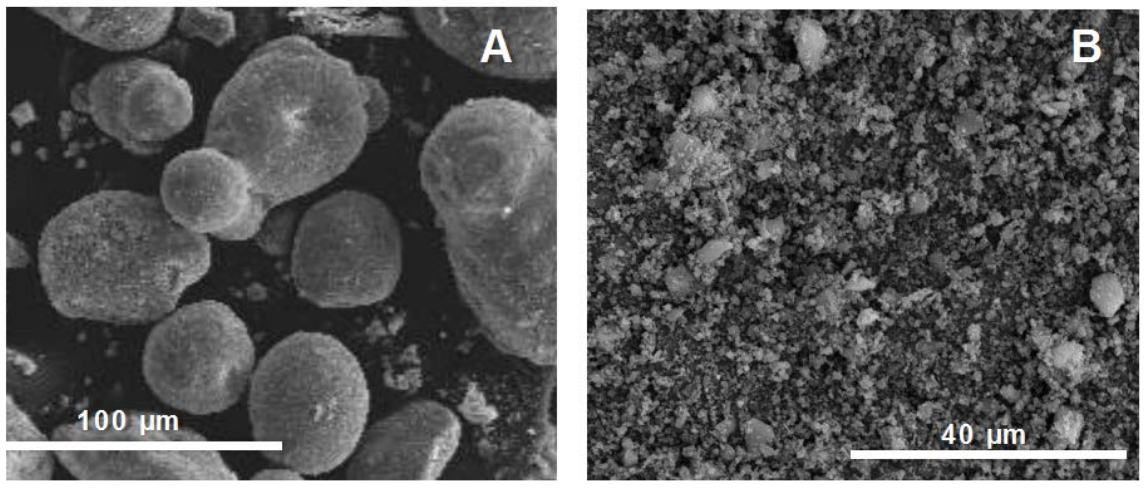

828

829 Figure 1. Scanning electron micrographs of A. untreated spent FCC catalyst 830 and B. ball-milled FCC catalyst.

831 


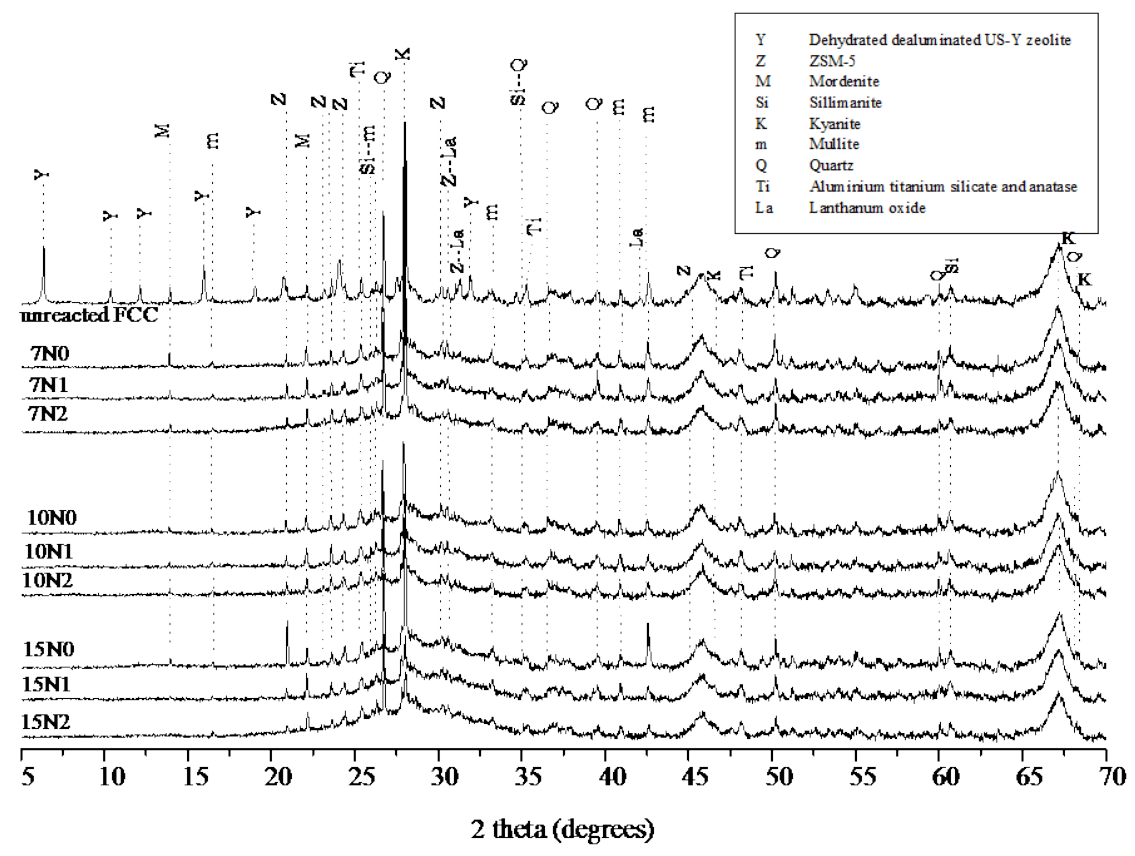

832

833

834

Figure 2. X-ray diffractograms of the unreacted spent FCC catalyst and geopolymers produced after 28 days of curing 


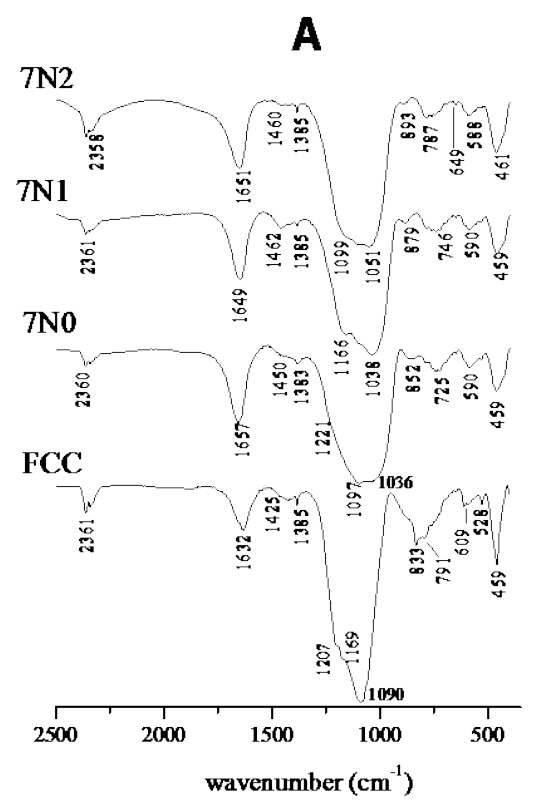

B
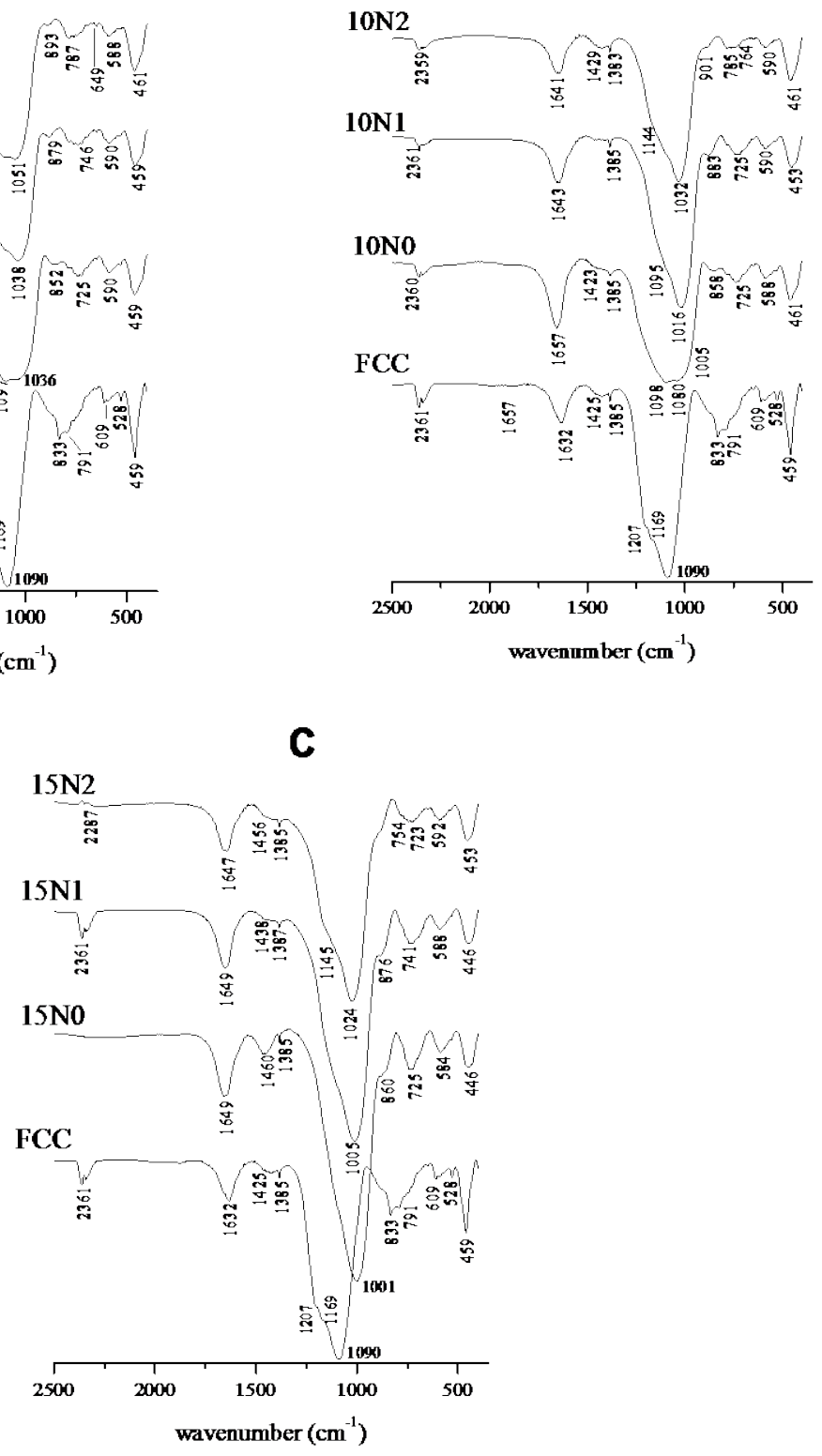

Figure 3. Fourier transform infrared spectra of alkali-activated spent FCC 836 | catalyst geopolymers after 28 days of curing. 

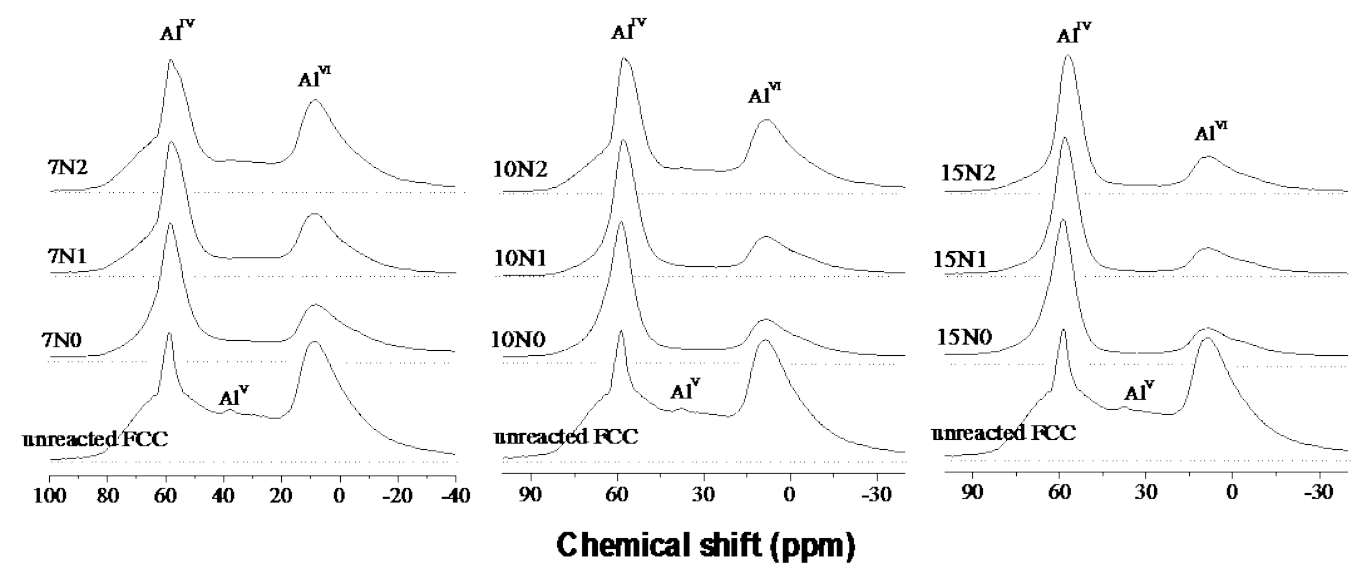

838

839

840

841
Figure 4. Solid state ${ }^{27} \mathrm{Al}$ MAS NMR spectra (14.1 T, $\left.v_{\mathrm{R}}=10 \mathrm{kHz}\right)$ of geopolymers, recorded after 28 days of curing. 


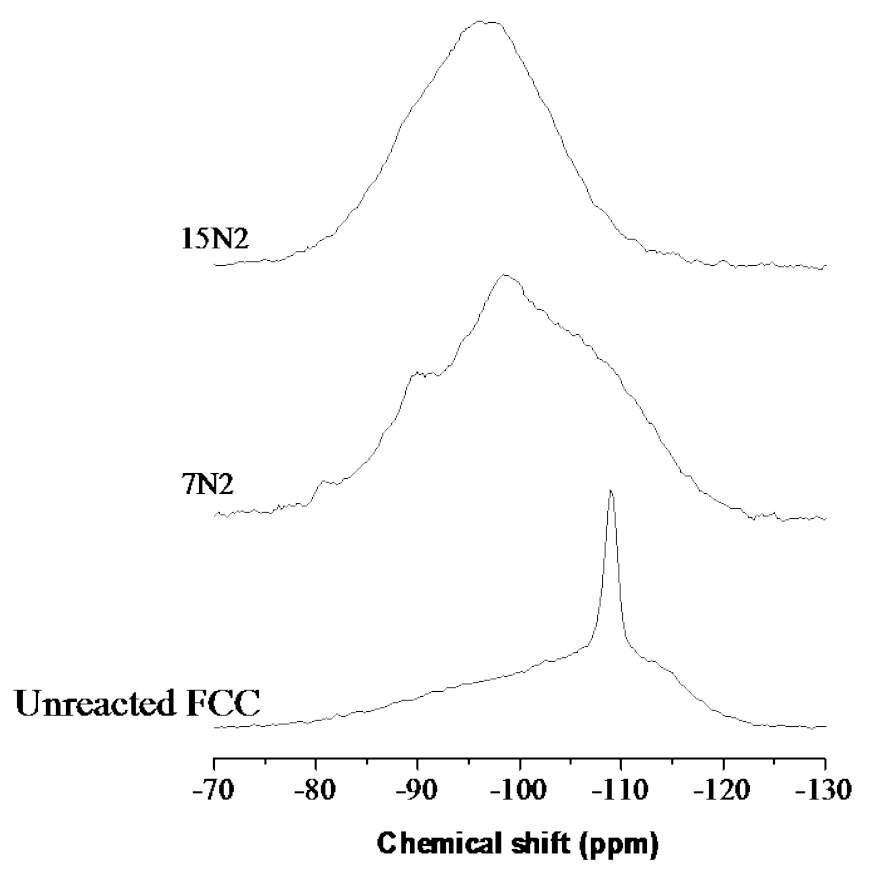

843

Figure 5. Solid state ${ }^{29} \mathrm{Si}$ MAS NMR spectra $\left(14.1 \mathrm{~T}, v_{\mathrm{R}}=10 \mathrm{kHz}\right)$ of geopolymers recorded after 28 days of curing 

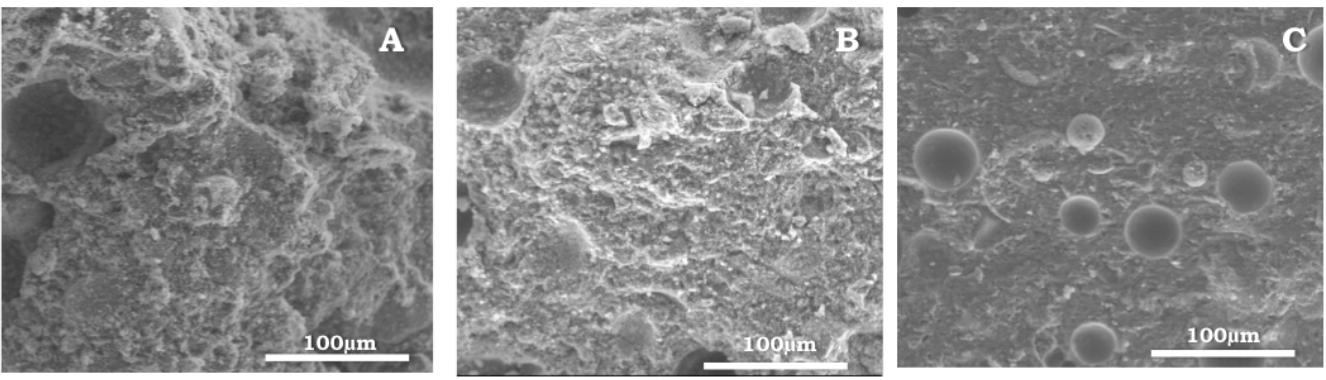

848

Figure 6. Scanning electron micrographs of pastes with different alkali content

849

(A. $7 \mathrm{~N} 1$, B. $10 \mathrm{~N} 1$, and C. $15 \mathrm{~N} 1$ ) after 28 days of curing.

850

851 

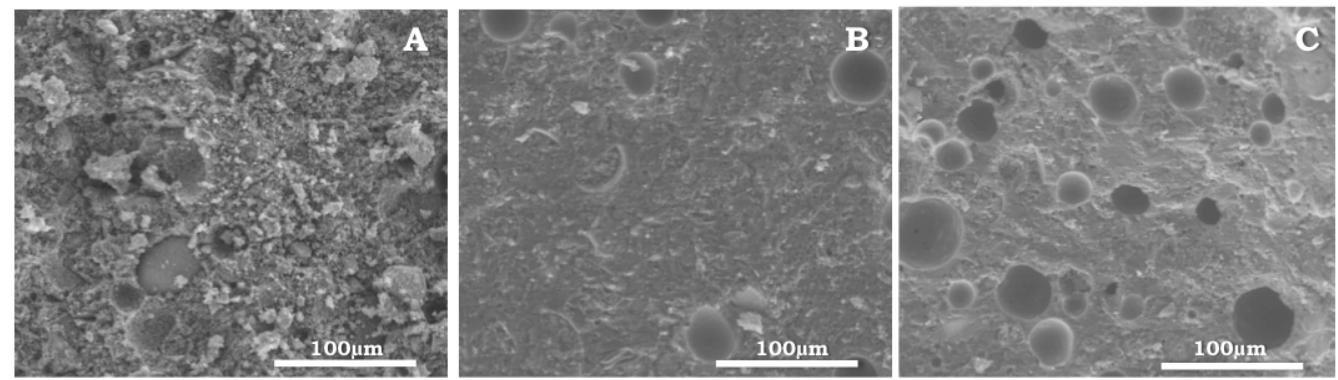

853

854

Figure 7. Scanning electron micrographs of pastes with different $\mathrm{SiO}_{2} / \mathrm{Na}_{2} \mathrm{O}$ ratio (A. $15 \mathrm{~N} 0$, B. $15 \mathrm{~N} 1$, and C. $15 \mathrm{~N} 2$ ) after 28 days of curing. 